Annals of International Medical and Dental Research

E-ISSN: 2395-2822 | P-ISSN: 2395-2814

Vol-8, Issue-2 | March-April 2022

DOI: 10.53339/aimdr.2022.8.2.25

Page no- 192-199 | Section- Research Article (Anaesthesia)

\title{
The Outcome of Covid-19 Positive Patients in a Covid Dedicated ICU, Associated with Comorbid Diseases: A Cross-Sectional Study
}

\author{
Muhammad Shamsul Arefin ${ }^{1 *}$, Asif-Ur-Rahman ${ }^{2}$, Md. Enamul Hoq ${ }^{3}$, Saifuddin AZM4, Md \\ Shahnewaz Parveg Tareq ${ }^{5}$, Anisur Rahman ${ }^{6}$, Daliya Nowsin 7 , Taima Rashika ${ }^{8}$, Numera Siddiqui ${ }^{9}$, \\ MD. Mazharul Alam¹0, Mohammed Mohidur Rahman'11
}

1Jr. Consultant, Department of Anaesthesia \& Intensive Care Medicine (ICU), Mugda Medical college \& Hospital, Dhaka. Email: dr.arefin20@gmail.com, Orcid ID: 0000-0002-8181-8431.

2Jr. Consultant, Department of Neuro-Anesthesiology, National Institute of Neurosciences \& Hospital (NINS), Agargaon, Dhaka, Bangladesh. Email: asifsoikot.as@gmail.com,

Orcid ID: 0000-0001-9007-1774.

${ }^{3}$ Assistant Professor (Medicine)Cumilla Medical College, Cumilla. Email: hoq_enam@yahoo.com,

Orcid ID: 0000-0002-2179-3527.

4Assistant Professor, Department of Neuro-Anesthesiology, National Institute of Neurosciences \& Hospital (NINS), Agargaon, Dhaka, Bangladesh.

Email: azmsaifuddin@gmail.com, Orcid ID: 0000-0001-5562-4249 ${ }_{5}^{5}$ Health programme officer, Delta Health Care Hospital Mirpur Limited. Email: dr.mdtareq@gmail.com,

Orcid ID: 0000-0001-9768-4717.

${ }^{6}$ Assistant Professor \& Head, Department of Anaesthesia \& Intensive Care Medicine (ICU), Mugda Medical college \& Hospital, Dhaka. Email: anisur123rangpur@gmail.com,

Orcid ID: 0000-0001-6511-0794.

7Medical Officer, ICU, Mugda Medical College \& Hospital. Email: daliya.mansur@gmail.com, Orcid: 0000-0001-7911-1085.

8 Medical Officer, Department of Neuro-Anesthesiology, National Institute of Neurosciences \& Hospital (NINS), Agargaon, Dhaka, Bangladesh.

Email: taima.rashika@gmail.com, Orcid ID: 0000-0002-4938-5488.

${ }^{9}$ Resident-Critical Care Medicine, Dhaka medical College \& Hospital. Orcid ID: 0000-0001-8840-8059.

10Pain Physician, Bangladesh Korea Friendship Hospital, Dhaka, Bangladesh. Email: mazhar.paincare@gmail.com,

Orcid ID: 0000-0003-0291-233X

11Jr. Consultant, Department of Neuro-Anesthesiology, National Institute of Neurosciences \& Hospital (NINS), Agargaon, Dhaka, Bangladesh. Email: shuvrodrmc@gmail.com,

Orcid ID: 0000-0002-3112-2209.

*Corresponding author

Received: 06 November 2021

Revised: 18 January 2022

Accepted: 31 January 2022

Published: 18 February 2022

\section{Abstract}

Background: Patients with Coronavirus Disease (COVID-19) have a significant death rate due to comorbid diseases. As a result, identifying risk factors associated with poor outcomes in COVID-19 patients is important. Objective: The aim of this study was to evaluate the admission and outcome status of the patients confirmed with Covid-19. Material \& Methods: This cross-sectional study was conducted at Mugda Medical College \& Hospital, Dhaka, Bangladesh during the period from April 2020 to September 2020. Total 205 patients with covid-19 were included in this study. Collection of data were checked and cleaned. After cleaning, the data were entered into computer and statistical analysis of the results being obtained by using windows-based computer software devised with Statistical Packages for Social Sciences version 24. Results: In this study among 205 patients. Most of the study people $41(20.0 \%)$ confirmed with covid-19 were admitted in September 2020. Followed by $20(9.76 \%)$ in April 2020, 33(16.09\%) in May 2020, 35(17.07\%) in June 2020, 38(18.53\%) in July 2020, 37(18.04\%) in August 2020 and $41(20.0 \%)$ in September. 23(11.21\%) highest death with covid-19 were admitted in July 2020. Most of the patients 104(50.73\%) were discharged with advice and 101(49.26\%) patients had expired. Out of 101 expired patients $92(91 \%)$ had comorbidities. The most common comorbidity amongst ICU admitted patients was respiratory syndrome (55 in number) and least common was hypertension (6 in number). Conclusions: The death rate for COVID-19 hospitalized patients is $49.26 \%$. The most prevalent comorbidities in individuals who died as a result of COVID-19 were respiratory syndrome, chronic kidney disease, hypertension, cardiovascular disease, and diabetes.

Keywords:- Admission Status, Outcome Status and Covid-19 Patients. 
Annals of International Medical and Dental Research E-ISSN: 2395-2822 | P-ISSN: 2395-2814

Vol-8, Issue-2 | March-April 2022

DOI: 10.53339/aimdr.2022.8.2.25

Page no- 192-199 | Section- Research Article (Anaesthesia)

\section{INTRODUCTION}

The novel corona virus, commonly known as Severe Acute Respiratory SyndromeCoronavirus-2 (SARS-CoV-2), is currently causing a pandemic throughout the world. SARS-CoV-2 infects lung alveolar epithelial cells by receptor-mediated endocytosis, as do other viruses, employing the angiotensin converting enzyme II (ACE2) as an entrance receptor.[1] Globally, there have been 234,809,103 confirmed cases of COVID-19, including 4,800,375 deaths, reported to WHO.[2] Following an epidemic of pneumonia cases with unknown causes in Wuhan City, Hubei Province, China, in December 2019, the World Health Organization (WHO) designated COVID-19 a pandemic on March 11, 2020.[3] Tyrell and Bynoe, who cultured the viruses from patients with common colds, originally identified coronaviruses in 1966.[4] Elderly people with co-morbid conditions including acute renal damage, diabetes, cardiovascular disease, cancer, and hypertension are more likely to die or have a more serious condition. [5,6] However, even younger and generally healthy people can also suffer from COVID-19-associated respiratory failure. [7] Pneumonia was the first clinical symptom of the SARS-CoV-2 linked illness. More recent studies, particularly among young children, indicate gastrointestinal symptoms and silent infections. So far, observations indicate a median incubation duration of three days (range: 0-24 days) and a mean incubation period of five days to seven days. [8] The percentage of people infected with SARSCoV2 who are asymptomatic throughout the duration of illness has yet to be determined.[9] The most frequent clinical symptoms in symptomatic individuals include fever and cough, as well as other nonspecific symptoms such as dyspnea, headache, muscular pain, and tiredness.110] SARS-CoV-2, causes severe acute respiratory syndrome which is linked to increased ICU mortality.[11] With the rise in confirmed instances of coronavirus disease (COVID-19) and the rising death toll in Bangladesh, early and efficient care of severely and critically sick patients appears to be crucial.[12] Because rates rely on the incidence of community testing and admission criteria, which differ by country, estimating hospital admission rates for people with covid-19 has proved to be challenging. However, one in ten to one in five individuals is expected to suffer a serious disease that necessitates hospitalization. [13] According to earlier WHO case definitions, patients were typically hospitalized with severe acute respiratory infection or severe acute respiratory syndrome. Intensive care is also provided differently in different nations.[14] Rate of ICU admission in covid positive patients ranged from 3\% to $100 \%$ and the mortality was $86 \%$ in ICU admitted patients as observed in 646 articles. [15] Old age, persistent significant comorbidity, and male sex have all been linked to an increased risk of death. $[16,17,18]$ There are few studies related to the admission and outcome status of confirmed Covid-19 patients in Bangladesh. Thus, this study was conducted to evaluate the admission and outcome status of patients confirmed with Covid-19.

\section{Objectives}

The aim of the study to assess the admission and outcome status of confirmed Covid-19 patients with co-morbidities admitted in ICU 
Annals of International Medical and Dental Research

E-ISSN: 2395-2822 | P-ISSN: 2395-2814

Vol-8, Issue-2 | March-April 2022

DOI: 10.53339/aimdr.2022.8.2.25

Page no- 192-199 | Section- Research Article (Anaesthesia)

of Mugda Medical College \& Hospital, Dhaka, Bangladesh.

\section{MATERIAL AND METHODS}

This cross-sectional study was conducted at ICU of Mugda Medical College \& Hospital, Dhaka, Bangladesh during the period of April 2020 to September 2020. Total 205 patients with covid-19 were included in this study. RT-PCR method was used to diagnose covid-19. Consent of the patients and guardians were taken before collecting data. After compilation, data were presented in the form of tables, figures and charts, as necessary. Inclusion criteria were all individuals diagnosed with covid-19 and all age groups. Exclusion criteria were individuals with negative result in diagnosis of covid-19 and patients transferred to another hospital. Numerical variables were expressed as mean and standard deviation, whereas categorical variables were count with percentage. Quantitative data among groups were analyzed by ANOVA test followed by exploration of significant difference between all possible paired group means by Bonferroni test. $\mathrm{P}$ value was less than 0.5 which is considered as statistically significant. Collection of data were checked and cleaned. After cleaning, the data were entered into computer and statistical analysis of the results being obtained by using windows-based computer software devised with Statistical Packages for Social Sciences version 24.

\section{RESULTS}

[Figure 1] shows the covid-19 confirmed patients admitted from April 2020 to September 2020. Most of the study people $41(20.0 \%)$ confirmed with covid-19 were admitted in September 2020. Followed by $20(9.76 \%)$ in April 2020, 33(16.09\%) in May 2020, 35(17.07\%) in June 2020, 38(18.53\%) in July 2020, 37(18.04\%) in August 2020 and $41(20.0 \%)$ in September. 23(11.21\%) highest death with covid-19 were admitted in July 2020. Followed by $8(3.90 \%)$ in April 2020, $20(9.75 \%)$ in May 2020, 22(10.73\%) in June 2020, 23(11.21\%) in July 2020, 21(10.24\%) in August 2020 and 7(3.41\%) in September. Out of 205 patients 152 had comorbidities (74\%). [Figure 2] shows majority of covid-19 confirmed patients admitted were female 144 $(70.24 \%)$ and $61(29.76 \%)$ were male. [Figure 3] demonstrates the comorbidities: 55 patients had respiratory syndrome, 40 patients had $\mathrm{DM}+\mathrm{HTN}, 17$ patients had CKD+DM+HTN, 14 patients had CKD, 13 patients had CKD+DM, 7 patients had DM, 6 patients had HTN. [Table 1] shows outcome of admitted patients. Out of 205 admitted patients at the ICU, 104 (50.73\%) were discharged with advice and 101 (49.26\%) had died. Out of expired 101 patients 92 (91.91\%) had comorbidities.

Table 1: Outcome of admitted confirmed covid-19 patient ( $\mathrm{n}=205)$.

\begin{tabular}{|l|l|l|}
\hline Outcome & n & \% \\
\hline Discharged with advice & 104 & 50.73 \\
\hline Death & 101 & 49.26 \\
\hline
\end{tabular}




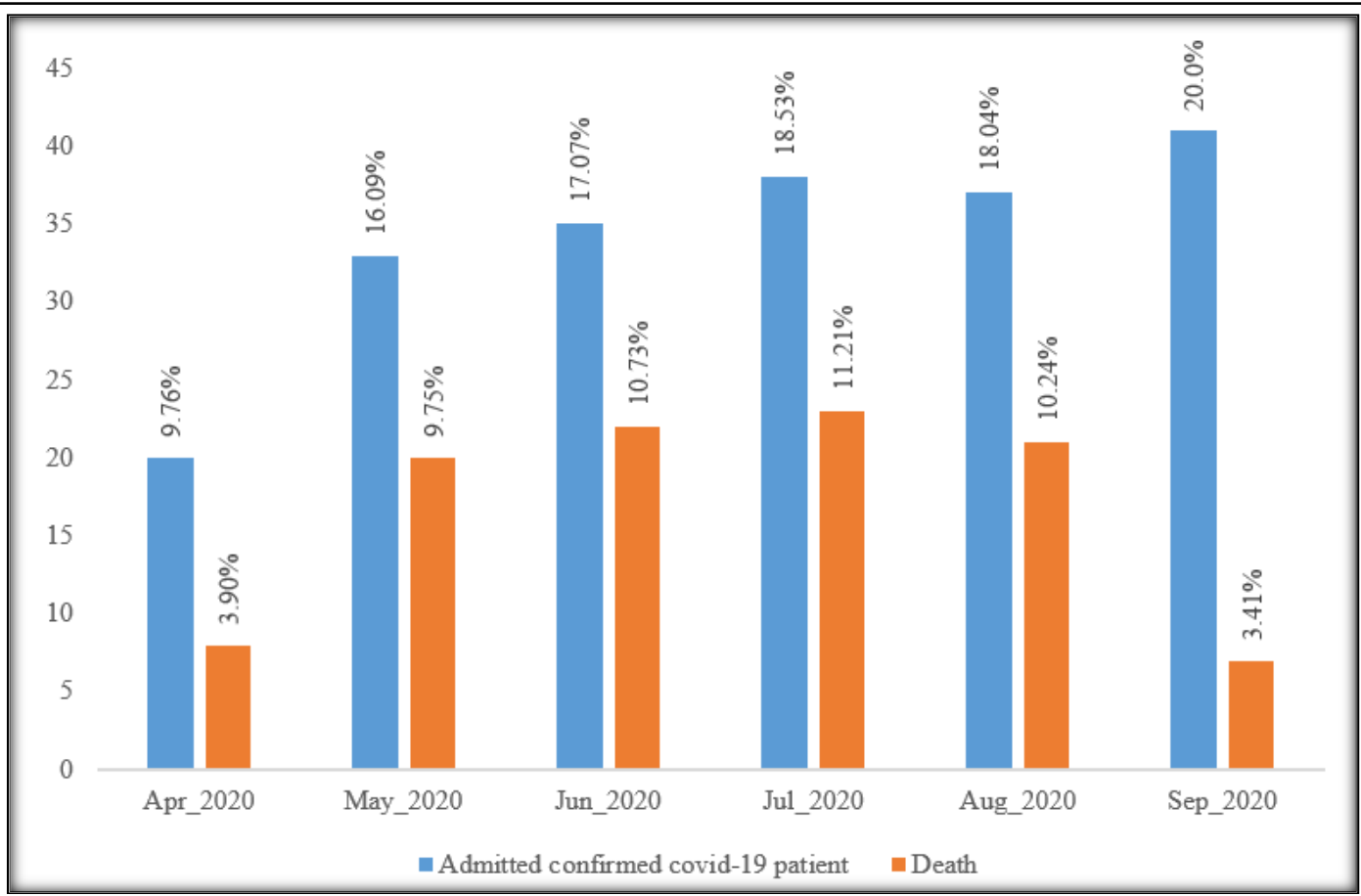

Figure 1: Distribution of the admitted confirmed covid-19 patient $(\mathrm{n}=205)$.

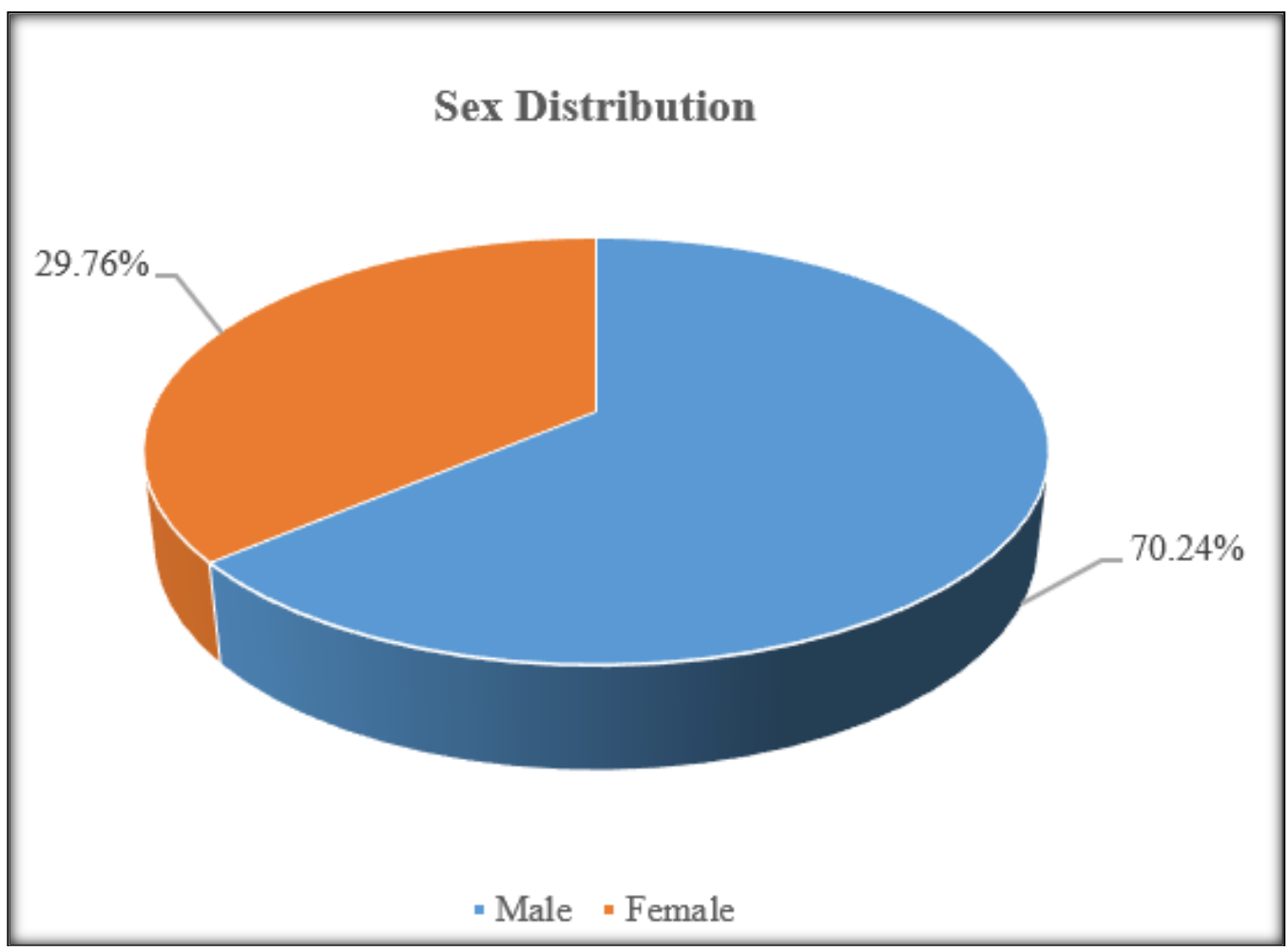

Figure 2: Distribution of the admitted confirmed covid-19 patient according to sex ( $\mathrm{n}=205)$. 


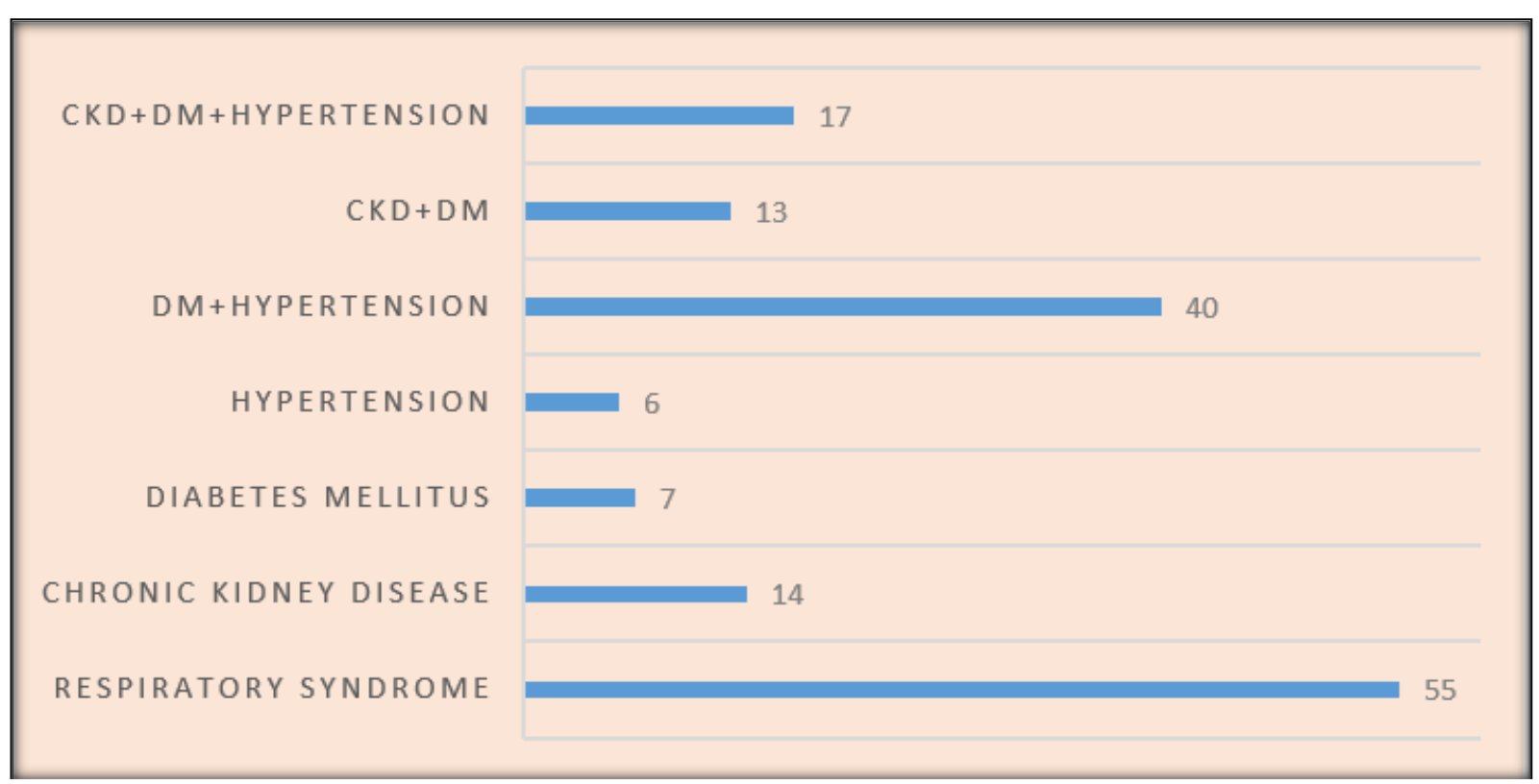

Figure 3: Distribution of the admitted confirmed covid-19 patient according to comorbidity.

\section{DISCUSSION}

In this study, the mortality rate was quite high 49.26\% (total patient admitted 205, expired 101). Out of 101 deceased patients 92 (91\%) had comorbidities. The high mortality rate indicates the co-relation between severity of the disease and the presence of comorbid conditions. A high mortality rate were also seen in a study conducted at New York City area, out of 5700 hospitalized patients the most common comorbidities were hypertension (3026; 56.6\%), obesity (1737; 41.7\%), and diabetes. The death rate was $21 \%$ in that study.[18] A study conducted at Dr. Wahidin Sudirohusodo Hospital, Makassar, Indonesia where 454 patients were included out of which 78 (17.18\%) had expired. The prevalent comorbidity in this study was hypertension $(42.31 \%)$, cardiovascular disease $(30.77 \%)$, diabetes $(28.21 \%)$, chronic kidney disease $(23.08 \%)$, malignancy $(15.38 \%)$, obesity
(15.38\%), chronic liver disease $(7.69 \%)$, chronic respiratory disease $(6.41 \%)$, immune related disease $(3.85 \%)$, and non-traumatic cerebral infarction (3.85\%). $41 \quad(52.56 \%)$ patients reported having two or more comorbidities, and $37(47.44 \%)$ only had one comorbidity.[19] Karyono DR and Wicaksana AL conducted their research on 28233 patients, the commonest comorbidities were hypertension $(52.1 \%)$, diabetes $(33.6 \%)$ and other cardiovascular diseases (20.9\%). Those three comorbidities caused greater proportion of deaths amongst other comorbidities.[20] Another study conducted on 66 million patients in France revealed that 3.8 million $(5.8 \%)$ were identified with diabetes, 11.9 million (18\%) with hypertension, 6.7 million $(10 \%)$ with dyslipidaemia or lipid-lowering drug intake, 5 million (7.6\%) with cardiovascular disease, 3.5 million (5.3\%) with chronic respiratory disease and 4.3 million $(6.5 \%)$ with neurotic or mood disorders or 
Annals of International Medical and Dental Research

E-ISSN: 2395-2822 | P-ISSN: 2395-2814

Vol-8, Issue-2 | March-April 2022

DOI: 10.53339/aimdr.2022.8.2.25

Page no- 192-199 | Section- Research Article (Anaesthesia)

antidepressant use. The absolute risk of inhospital mortality exceeded 300 per 100,000 in six conditions: end-stage renal disease on dialysis, dementia (including Alzheimer's disease), lung transplantation, heart failure, active lung cancer and kidney transplantation. [21] A review article paper conducted from January to April 20, 2020 concluded that patients with COVID-19 disease with comorbidities like hypertension or diabetes mellitus are more likely to develop a more severe course and worse prognosis. On the other hand, COVID-19 infected patients 65 years old and above with comorbidities, had an increased admission rate into the intensive care unit (ICU) and mortality.[22] In a retrospective analysis of medical records for 2184 laboratory confirmed cases of COVID-19 in Lagos, southwest Nigeria 492 patients $(22.5 \%)$ had at least one comorbidity and the commonest comorbidity were hypertension (74.2\%) and diabetes (30.3\%). The mortality rate was $3.3 \%$ and a significantly higher proportion of patients with comorbidities died compared to those with none.[23] Guan WJ et al. analyzed data from 1590 laboratory confirmed hospitalized patients from 575 hospitals in 31 provinces China. 399 (25.1\%) had at least one comorbidity. The commonest were hypertension $(16.9 \%)$ and then diabetes $(8.2 \%) .130(8.2 \%)$ patients presented with two or more comorbidities. At least one comorbidity was observed commonly in severe cases in comparison to non-severe cases (32.8\% versus $10.3 \%$ ). Older patients with at least one comorbidity (mean age 60.8 versus 44.8 years) were more likely to have shortness of breath $(41.4 \%$ versus $17.8 \%)$, nausea or vomiting (10.4\% versus $4.3 \%)$, and manifested abnormal chest radiograph (29.2\% versus $15.1 \%) .[24]$ In a
Bangladeshi study conducted on 405 hospital admitted cases, the prevalence of specific comorbidities were: hypertension $(n=141$, $34.8 \%)$, other cardiovascular diseases $(n=42$, $10.4 \%)$ cerebrovascular diseases $(n=7,1.7 \%)$, diabetes $(n=140,34.6 \%)$, COPD $(n=4,1.0 \%)$, chronic kidney diseases $(n=65,16.0 \%)$, malignancy $(n=4,1.0 \%)$ and asthma $(n=51$, 12.6\%). Overall, 307 (75.8\%) patients were discharged alive, 98 (24.2\%) patients expired, $63(15.6 \%)$ were shifted to the ICU and 16 $(4.0 \%)$ were put into invasive ventilation. [25]

In our study period, total 205 patients were admitted. Among them 152 had comorbidities out of which 70 patients had $\geq 2$ comorbidities. Comorbidities observed were as such: 55 with Respiratory syndrome, 40 with DM and HTN, 17 with CKD+DM+HTN, 14 with CKD, 13 with CKD+DM, 7 with DM and 6 with HTN. Total 101 patients died, out of which 92 (91.91\%) had comorbidities.

\section{Limitation of the study}

In our study, there was small sample size. Study population was selected from one center in Dhaka city, so may not represent wider population. The study was conducted at a short period of time. The sampling was retrospective and there was no random allocation, so there is risk of selection bias.

\section{CONCLUSIONS}

The death rate of COVID-19 positive patients was $49.26 \%$ (101 out of 205). The most prevalent comorbidities were respiratory syndrome, hypertension, cardiovascular disease, and diabetes. Out of the 101 expired patients 92 (91.91\%) had comorbidities. 
Annals of International Medical and Dental Research

E-ISSN: 2395-2822 | P-ISSN: 2395-2814

Vol-8, Issue-2 | March-April 2022

DOI: 10.53339/aimdr.2022.8.2.25

Page no- 192-199 | Section- Research Article (Anaesthesia)

\section{Recommendation}

This study can serve as a pilot to a much larger research involving multiple centers that can provide a nationwide picture, validate regression models proposed in this study for future use and emphasize points to ensure better management and adherence. Further studies are needed with larger sample to have better results. Follow up data might be included in further study.

\section{REFERENCES}

1. Zhou P, Yang XL, Wang XG, Hu B, Zhang L, Zhang $\mathrm{W}$, et al. A pneumonia outbreak associated with a new coronavirus of probable bat origin. Nature. 2020;579(7798):270-273. doi: 10.1038/s41586-020-20127.

2. Dong E, Du H, Gardner L. An interactive web-based dashboard to track COVID-19 in real time. Lancet Infect Dis. 2020;20(5):533-534. doi: 10.1016/S14733099(20)30120-1.

3. Cucinotta D, Vanelli M. WHO Declares COVID-19 a Pandemic. Acta Biomed. 2020;91(1):157-160. doi:10.23750/abm.v91i1.9397

4. Tyrrell DA, Bynoe ML. Cultivation of viruses from a high proportion of patients with colds. Lancet. 1966;1(7428):76-7. doi: 10.1016/s0140-6736(66)923646.

5. Yanez ND, Weiss NS, Romand JA, Treggiari MM. COVID-19 mortality risk for older men and women. BMC Public Health. 2020;20(1):1742. doi: 10.1186/s12889-020-09826-8.

6. Djaharuddin I, Munawwarah S, Nurulita A, Ilyas M, Tabri NA, Lihawa N. Comorbidities and mortality in COVID-19 patients. Gac Sanit. 2021;35 Suppl 2:S530S532. doi: 10.1016/j.gaceta.2021.10.085.

7. Abbasi J. Younger Adults Caught in COVID-19 Crosshairs as Demographics Shift. JAMA. 2020;324(21):2141-2143. doi: 10.1001/jama.2020.21913.

8. Wiersinga WJ, Rhodes A, Cheng AC, Peacock SJ, Prescott HC. Pathophysiology, Transmission, Diagnosis, and Treatment of Coronavirus Disease

\section{Acknowledgements}

The wide range of disciplines involved in Covid-19 Positive Patients in Mugda ICU Associated with Comorbid Diseases research means that the editors needs much assistance from referees in the evaluation of papers submitted for publication. I am very grateful to many colleagues for their thorough, helpful and usually prompt response to requests for their opinion and advice.

2019 (COVID-19): A Review. JAMA. 2020;324(8):782793. doi: 10.1001/jama.2020.12839.

9. Ma Q, Liu J, Liu Q, Kang L, Liu R, Jing W, et al. Global Percentage of Asymptomatic SARS-CoV-2 Infections Among the Tested Population and Individuals With Confirmed COVID-19 Diagnosis: A Systematic Review and Meta-analysis. JAMA Netw Open. 2021;4(12):e2137257. doi: 10.1001/jamanetworkopen.2021.37257.

10. Zaim S, Chong JH, Sankaranarayanan V, Harky A. COVID-19 and Multiorgan Response. Curr Probl Cardiol. 2020;45(8):100618. doi:10.1016/j.cpcardiol.2020.100618

11. Wang W, Tang J, Wei F. Updated understanding of the outbreak of 2019 novel coronavirus (2019-nCoV) in Wuhan, China. J Med Virol. 2020;92(4):441-447. doi: 10.1002/jmv.25689.

12. Anwar S, Nasrullah M, Hosen MJ. COVID-19 and Bangladesh: Challenges and How to Address Them. Front Public Health. 2020;8:154. doi:10.3389/fpubh.2020.00154

13. Verity R, Okell LC, Dorigatti I, Winskill P, Whittaker C, Imai $\mathrm{N}$, et al. Estimates of the severity of coronavirus disease 2019: a model-based analysis. Lancet Infect Dis. 2020;20(6):669-677. doi: 10.1016/S1473-3099(20)30243-7.

14. Fitzner J, Qasmieh S, Mounts AW, et al. Revision of clinical case definitions: influenza-like illness and severe acute respiratory infection. Bull World Health Organ. 2018;96(2):122-128. doi:10.2471/BLT.17.194514

15. Abate SM, Ahmed Ali S, Mantfardo B, Basu B. Rate of Intensive Care Unit admission and outcomes among 
Annals of International Medical and Dental Research

E-ISSN: 2395-2822 | P-ISSN: 2395-2814

Vol-8, Issue-2 | March-April 2022

DOI: 10.53339/aimdr.2022.8.2.25

Page no- 192-199 | Section- Research Article (Anaesthesia)

patients with coronavirus: A systematic review and Meta-analysis. PLoS One. 2020;15(7):e0235653. doi:10.1371/journal.pone.0235653

16. Chen N, Zhou M, Dong X, Qu J, Gong F, Han Y, et al. Epidemiological and clinical characteristics of 99 cases of 2019 novel coronavirus pneumonia in Wuhan, China: a descriptive study. Lancet. 2020;395(10223):507-513. doi: 10.1016/S01406736(20)30211-7.

17. Onder G, Rezza G, Brusaferro S. Case-Fatality Rate and Characteristics of Patients Dying in Relation to COVID-19 in Italy. JAMA. 2020;323(18):1775-1776. doi: 10.1001/jama.2020.4683.

18. Richardson S, Hirsch JS, Narasimhan $M$, et al. Presenting Characteristics, Comorbidities, and Outcomes Among 5700 Patients Hospitalized With COVID-19 in the New York City Area. JAMA. 2020;323(20):2052-2059. doi:10.1001/jama.2020.6775

19. Djaharuddin I, Munawwarah S, Nurulita A, Ilyas M, Tabri NA, Lihawa N. Comorbidities and mortality in COVID-19 patients. Gac Sanit. 2021;35 Suppl 2:S530S532. doi:10.1016/j.gaceta.2021.10.085

20. Karyono DR, Wicaksana AL. Current prevalence, characteristics, and comorbidities of patients with COVID-19 in Indonesia. J Community Empowerment Health. 2020;3(2):77-84.

21. Semenzato L, Botton J, Drouin J, Cuenot F, DraySpira R, Weill A, Zureik M. Chronic diseases, health conditions and risk of COVID-19-related hospitalization and in-hospital mortality during the first wave of the epidemic in France: a cohort study of 66 million people. Lancet. 2021;8:100158.

22. Sanyaolu A, Okorie C, Marinkovic A, et al. Comorbidity and its Impact on Patients with COVID19. SN Compr Clin Med. 2020;2(8):1069-1076. doi:10.1007/s42399-020-00363-4

23. Osibogun A, Balogun M, Abayomi A, Idris J, Kuyinu Y, Odukoya O, et al. Outcomes of COVID-19 patients with comorbidities in southwest Nigeria. PLoS One. 2021;16(3):e0248281.

doi: 10.1371/journal.pone.0248281.

24. Guan WJ, Liang WH, Zhao Y, et al. Comorbidity and its impact on 1590 patients with COVID-19 in China: a nationwide analysis. Eur Respir J. 2020;55(5):2000547. doi:10.1183/13993003.00547-2020

25. Hossain I, Mullick AR, Khan MH, Halim KS, Aktaruzzaman MM, Nabi SG, et al. Comorbidity and it, s Impact on COVID-19 Affected Patients in COVID-19 Dedicated Hospital of Bangladesh. Bangladesh Med J. 2020;49(1):19-25.

Source of Support: Nil, Conflict of Interest: None declared 